\title{
MAPEAMENTO DOS BAIRROS SUSCETÍVEIS À INUNDAÇÕES NO MUNICÍPIO DE JAÚ-SP
}

\author{
MAPPING NEIGHBORHOODS OF SUSCEPTIBLE TO FLOODING IN THE CITY OF \\ JAÚ-SP
}

\author{
Keila Camila da Silva ${ }^{1}$ \\ Cristiano Poleto ${ }^{2}$
}

\begin{abstract}
Resumo: Inundações são fenômenos que ocorrem em diversas regiões do mundo, caracterizadas por situações onde ocorre o transbordamento do rio. Normalmente as maiores proporções ocorrem em áreas urbanas. Usa-se o nome de enchente para a situação natural de transbordamento de água do leito do rio, já as inundações estão relacionadas à intensificação desse processo por ações humanas, ocasionando danos, prejuízos e modificações na dinâmica natural. A identificação das áreas de risco de inundações, através do mapeamento é um instrumento para o controle e prevenção desse desastre. Esse trabalho procurou mapear pontos de risco de inundação no município de Jaú, localizado na região central do estado de São Paulo. As inundações no município foram classificadas em graduais e bruscas, sendo a primeira, aquelas que ocorrem em bairros próximos ao rio, com seu transbordamento, e a segunda, ocorrem devido a drenagem inexistente/ineficiente.
\end{abstract}

Palavras-chave: Áreas de Risco. Inundação. Mapeamento.

\begin{abstract}
Floods are phenomena occurring in different regions of the world, characterized by situations where the overflow of the river occurs. Typically the highest proportions occurs in urban areas. Uses the name of the natural situation of flood water overflow from the river bed, since floods are related to this process intensified by human activities, causing damages, losses and changes in the natural dynamics. The identification of areas at risk of flooding by mapping is a tool to control and prevent this disaster. This study sought to map points flood risk in the town of Jau, located in the central region of the state of São Paulo. The floods in the city have been classified into gradual and abrupt, first, those that occur in neighborhoods close to the river, with its overflowing, and the second being, occur due to missing / inefficient drainage.
\end{abstract}

Keywords: Risk Areas. Flood. Mapping.

\section{INTRODUÇÃO}

As inundações urbanas vêm ocasionando um dos principais tipos de desastres urbanos e que afetam uma grande parcela da população em vários municípios brasileiros. A ocupação desordenada nas grandes cidades, acompanhada de um aumento populacional, ocasiona um cenário de muitas modificações no ambiente natural e urbano, dentre essas, encontram-se as inundações.

Muitos transtornos são enfrentados, em termos socioeconômicos, observa-se a perda de vidas, perdas materiais além das ambientais. Os mais prejudicados por esses eventos são aquelas pessoas que vivem às periferias das cidades, onde estão mais propensas às enchentes.

Nos dias atuais, as inundações são resultadas da modificação do ambiente natural pela ação humana, ocasionando o crescimento rápido, desordenado e não planejado das cidades. Devido a isso, as enchentes, consideradas como desastres naturais, hoje, nas cidades são as temidas inundações:

\footnotetext{
${ }^{1}$ Rua Jorge Buchalla, 79, Jd. América, 17210670 - Jaú-SP.

${ }^{2}$ Av. Bento Gonçalves, 9500, 91501970 - Porto Alegre, RS.
} 
A ocorrência de inundações em centros urbanos é tão antiga quanto às cidades ou qualquer aglomerado urbano. A inundação ocorre quando as águas dos rios, riachos, galerias pluviais saem do leito de escoamento devido à falta de capacidade de transporte de um destes sistemas e ocupa áreas onde a população utiliza para moradia, transporte, recreação, comércio, indústria, entre outros (Tucci, 2007).

Nesse contexto ambiental, o risco é eminente, trazendo impactos ambientais e sociais. O reconhecimento das áreas de inundações através das zonas de risco, através do mapeamento vem sendo um instrumento essencial tanto para o controle como para prevenção desse desastre, através do mesmo é possível definir as áreas de risco. Jaú, um município localizado na região central do estado de São Paulo e, segundo o (IBGE, 2010), com uma população em torno de 140.000 habitantes, sofre constantes cheias dos rios e córregos que passam pelo seu trecho urbano. Dessa forma, o objetivo dessa pesquisa foi reconhecer e mapear as áreas sujeitas a inundações.

Dentre as causas das inundações no município, identificou-se que os problemas são, além da ocorrência de chuvas e de mal planejamento urbano, decorrentes também da falta de conscientização da população em relação ao ambiente natural. Segundo Moretti (2000) o fato de nos dias atuais as cheias não serem tão bem-vindas está ligado com o fato da população nos últimos anos ter se distanciado fisicamente, socialmente e culturalmente dos rios.

\section{MATERIAIS E MÉTODOS}

\section{1 ÁREA DE ESTUDO}

A área de estudo desta pesquisa abrangeu o município de Jaú-SP (Figura 1), localizado na região central do estado de São Paulo. O município é um importante pólo de desenvolvimento industrial e agrícola, destacando-se pela grande quantidade de indústrias de calçados, sendo conhecido como a capital do calçado feminino. Encontra-se a $296 \mathrm{~km}$ da capital do estado. Geograficamente, possui área total de aproximadamente $688,34 \mathrm{Km}^{2}$, da qual $16,33 \mathrm{Km}^{2}$ são das áreas urbanas e $672,01 \mathrm{Km}^{2}$ são áreas rurais. Encontrando-se nas posições geográficas: latitude: $22^{0} 17^{\prime} 47^{\prime \prime} \mathrm{S}$, longitude: $48^{0} 33^{\prime} 28^{\prime \prime} \mathrm{O}$ e altitude: 522 metros. Quanto a suaclimatologia,observa-se uma média anual entre $22,8^{0} \mathrm{C}$, máxima de $36^{\circ} \mathrm{C}$ e mínima de $18^{0} \mathrm{C}$, aproximadamente. Na Figura 1, a seguir, observa-se a localização do município:

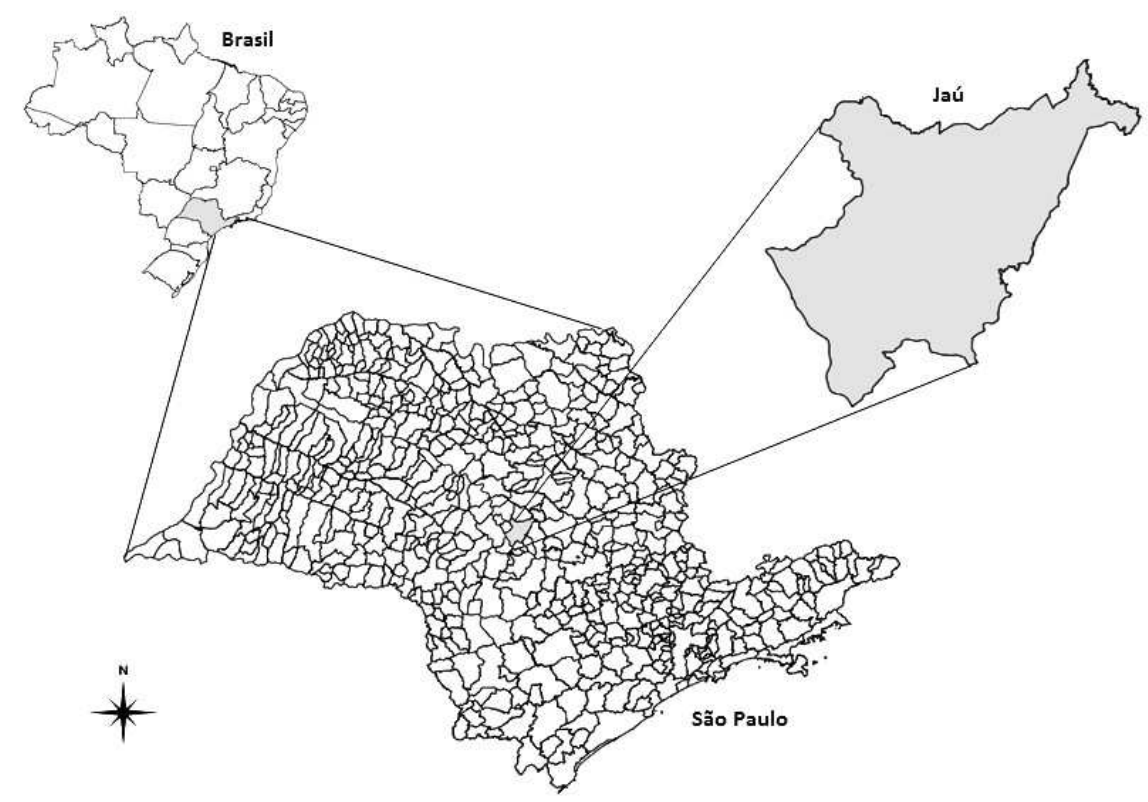

Figura 1. Localização do município de Jaú-SP 
O município de Jaú apresenta toda sua área dentro da Unidade de Gerenciamento de Recursos Hídricos Tietê-Jacaré (UGRHI-TJ), na figura 2. A Bacia Hidrográfica do Rio Jaú, localizada no centro-oeste do estado de São Paulo, faz parte da Bacia Hidrográfica do TietêJacaré.

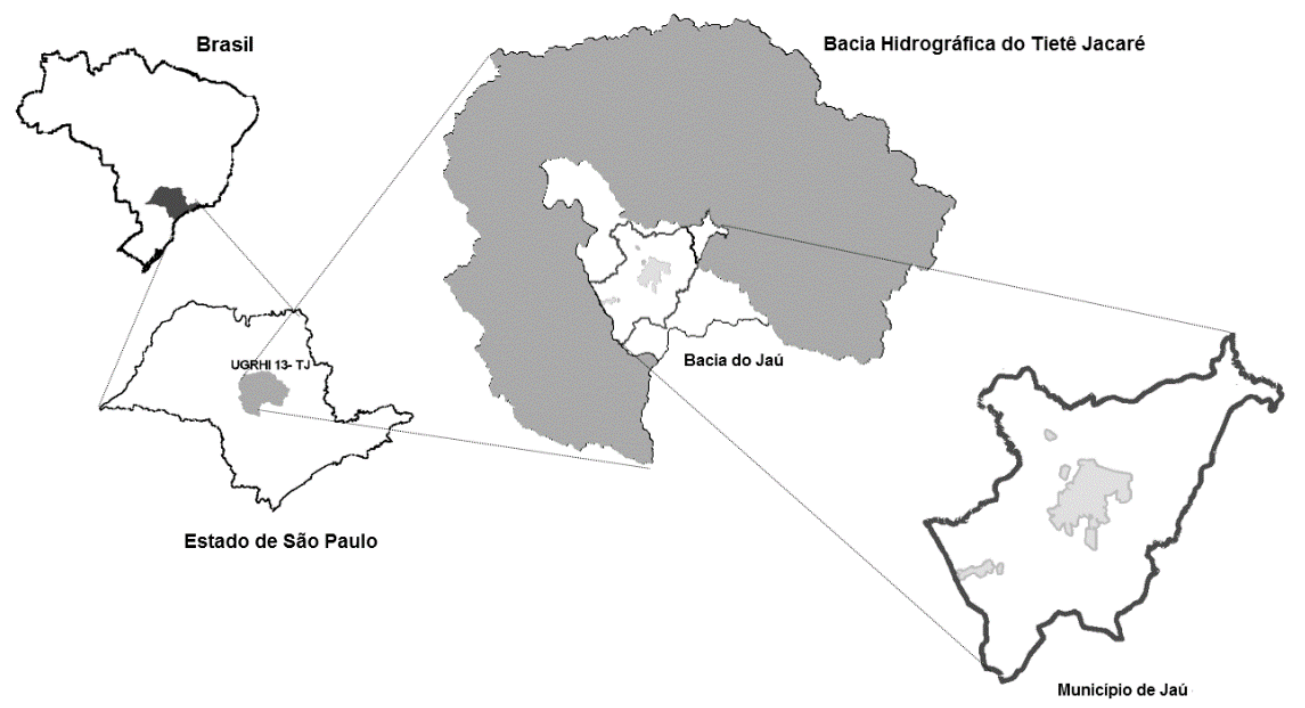

Figura 2. Localização do município dentro da bacia

Demograficamente a população vem sofrendo um aumento ao longo dos anos (Tabela 1), segundo dados dos censos do IBGE (2010), e hoje se aproxima de 140.000 habitantes.

Tabela 1. Aumento populacional no município (IBGE, 2010).

\begin{tabular}{|c|c|c|c|c|c|c|c|c|c|}
\hline Ano & $\mathbf{1 9 2 0}$ & $\mathbf{1 9 4 0}$ & $\mathbf{1 9 5 0}$ & $\mathbf{1 9 6 0}$ & $\mathbf{1 9 7 0}$ & $\mathbf{1 9 8 0}$ & $\mathbf{1 9 9 0}$ & $\mathbf{2 0 0 0}$ & $\mathbf{2 0 1 0}$ \\
\hline Jaú & 42.586 & 44.141 & 54.161 & 56.301 & 74.028 & 94.116 & 103.601 & 131.068 & 132.494 \\
\hline
\end{tabular}

Economicamente, o município é polo industrial calçadista e da agroindústria devido à cana-de-açúcar. Possui agricultara desenvolvida principalmente pela cana-de-açúcar, o café, frutas e algodão, devido ao tipo de solo predominante ser muito fértil, o latossolo roxo. Seus limites territoriais se dão ao norte com o município de Bocaina, à Nordeste com Dourados, a Leste com Dois Córregos, Sudeste com barra Bonita e Mineiros do Tietê, Oeste com Pederneiras e Itapuí e Noroeste com Bariri. Dados do IBGE, (Figura 3), mostram o decréscimo da população rural e o aumento da população urbana no período de 1950 à 2010. 


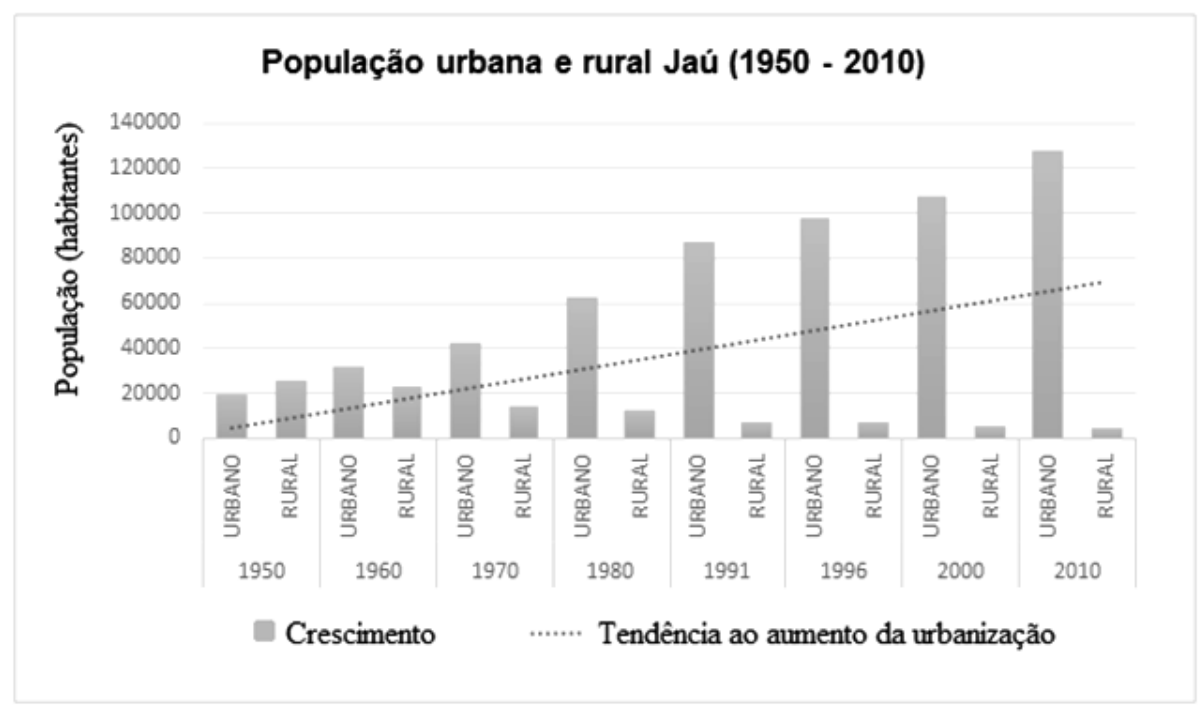

Figura 3. Urbanização no município de Jaú

O município de Jaú, é cortado por um vale fluvial, o Vale do Rio Jaú, por esse motivo enfrentou, e ainda enfrenta, problemas relacionados às inundações, comuns nos períodos mais chuvosos (dezembro à março). Além dos aspectos já mencionados, a cidade de Jaú possui um sistema de drenagem ineficiente para escoar toda a água pluvial quando das ocorrências de chuvas intensas rápidas, ou ainda de chuvas contínuas. Quanto aouso e cobertura do solo do município de Jaú, sua maior extensão territorial corresponde à área ocupada pela atividade do plantio de cana-de-açúcar. As matas ciliares representam 7\% da área territorial, distribuindose ao longo das margens dos cursos d'água do município.

\subsection{BAIRROS DE INUNDAÇÕES}

O mapeamento de áreas de risco de enchentes e inundações, em princípio, teve como objetivo enquadrar os bairros em pontos de inundações. Primeiramente, foram identificados trinta e nove pontos suscetíveis a inundações com a ajuda da Defesa Civil municipal. Após a identificação dos pontos ou bairros, iniciou-se a avaliação da área a fenômenos de inundações. Embasado no Mapa Rodoviário de Jaú de 1980, vetorizado a partir das cartas topográficas do IBGE de 1973 e do Mapa de Risco de 2012 do Departamento de Defesa Civil.

Pontos obtidos através do aparelho GPS Garmin eTrex Vista ${ }^{\circledR}$, calibrado no marco geodésico na Estação Hidrometeorológica IBICA-RE-IG, instalado à Latitude S $22^{\circ} 18^{\prime} 50^{\prime \prime}$ e Longitude: O 48 32' 54" Altitude: 583,4 metros (SIRGAS 2000). Organização e manipulação das informações através do software AutoCAD 2014 - Versão Educacional ®, em escala real (1:1). Utilizou-se o seguinte critério para caracterização dos pontos de risco de inundação (Tabela 2).

Tabela 2. Critério para enquadramento de inundações

\begin{tabular}{l|l}
\hline Tipo de Inundação & $\begin{array}{l}\text { Inundações que ocorrem devido ao transbordamento do rio/córrego. } \\
\text { Ocorrem em bairros próximos ao rio. }\end{array}$ \\
\hline Graduais & $\begin{array}{l}\text { Inundações que ocorrem devido a inexistência de drenagem urbana no bairro } \\
\text { ou drenagem ineficiente. }\end{array}$ \\
Graduais e Bruscas & $\begin{array}{l}\text { Inundações que ocorrem tanto pela inexistência/ineficiência da drenagem, } \\
\text { como pela proximidade ao rio. }\end{array}$ \\
\hline
\end{tabular}




\section{RESULTADOS E DISCUSSÕES}

De acordo com os dados obtidos sobre o histórico de inundações no município ao longo dos anos, identificou-se que as inundações vêm ocorrendo ao longo dos anos, devido principalmente a falta de ações preventivas, por parte do governo e da própria população, a falta de investimento em ações de recuperação de cenários afetados por desastres naturais, ocasionando o aumento de eventos.

Dentre os principais fatores contribuintes para as inundações no município observa-se a falta de planejamento e drenagem urbana em muitos pontos, assim como o desmatamento da bacia hidrográfica, ocasionando um aumento das áreas impermeáveis, seguido pelo aumento populacional. Além desses fatores, o comportamento inadequado da população e o elevado índice pluviométrico intensificam esse problema.

Segundo (Tucci, 2005), a gestão e o combate ao risco à inundação acontecem através da utilização de medidas de controle da inundação que visam tornar mínimo o risco das populações que estão expostas, diminuindo os prejuízos causados. Essas medidas podem ser do tipo estrutural e não estrutural. A análise e classificação dos bairros pode ser observada na Tabela 3.

Tabela 3: Pontos/bairros de inundações no município

\begin{tabular}{|c|c|c|}
\hline Graduais e Bruscas & Graduais & Bruscas \\
\hline $\mathbf{1}^{\circ}$ Centro & $4^{\mathbf{0}}$ Condomínio Estância & 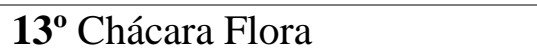 \\
\hline $\mathbf{2}^{\mathbf{0}}$ Jardim Maria Luiza IV & Soave & $\mathbf{1 4}^{\mathbf{0}}$ Chácara Bela Vista \\
\hline $3^{\mathbf{0}}$ Jardim São José & $5^{\circ}$ Distrito de Potunduva & $\mathbf{1 5}^{\circ}$ Condomínio Concha de \\
\hline & $6^{\mathbf{0}}$ Jardim Bela Vista & Ouro \\
\hline & $7^{\mathbf{0}}$ Jardim Sempre Verde & $\mathbf{1 6}^{\mathbf{0}}$ Condomínio Jardim \\
\hline & $8^{\circ}$ Pouso Alegre de Baixo & Alvorada \\
\hline & $9^{\circ}$ Vila Ivan & $\mathbf{1 7}^{\mathbf{0}} \mathrm{Jardim}$ América \\
\hline & $\mathbf{1 0}^{\mathbf{0}}$ Vila Maria Cristina & $\mathbf{1 8}^{\mathbf{0}}$ Jardim Brasília \\
\hline & $\mathbf{1 1}^{\mathbf{0}}$ Vila Ribeiro & $\mathbf{1 9}^{\mathbf{0}}$ Jardim Cila Lúcio Bauab \\
\hline & $\mathbf{1 2}^{\mathbf{0}}$ Vila São Judas Tadeu & $\mathbf{2 0}^{\mathbf{6}}$ Jardim Julliana \\
\hline & & $\mathbf{2 1}^{\mathbf{0}}$ Jardim Maria Cibele \\
\hline & & $\mathbf{2 2}^{\mathbf{0}}$ Jardim Nova Jaú \\
\hline & & $\mathbf{2 3}^{\mathbf{0}}$ Jardim Novo Horizonte \\
\hline & & $\mathbf{2 4}^{\mathbf{0}}$ Jardim Orlando Ometto \\
\hline & & $\mathbf{2 5}^{\mathbf{0}}$ Jardim Parati \\
\hline & & $\mathbf{2 6}^{\mathbf{0}}$ Jardim Padre Augusto Sani \\
\hline & & $27^{\mathbf{0}}$ Jardim Pedro Ometto \\
\hline & & $\mathbf{2 8}^{\mathbf{0}}$ Jardim Santa Rosa \\
\hline & & $\mathbf{2 9}^{\mathbf{0}}$ Jardim São Crispim \\
\hline & & $\mathbf{3 0}^{\mathbf{0}}$ Jardim Santo Antônio \\
\hline & & $\mathbf{3 1}^{\mathbf{0}}$ Jardim Santo Onofre \\
\hline & & $\mathbf{3 2}^{\mathbf{0}}$ Jardim Sanzovo \\
\hline & & 33' $^{\mathbf{2}}$ Residencial Bernardi \\
\hline & & $\mathbf{3 4}^{\mathbf{o}}$ Residencial Itamarati \\
\hline & & $\mathbf{3 5}^{\circ}$ Residencial João Ballan I \\
\hline & & $\mathbf{3 6}^{\mathbf{0}}$ Residencial Márcio \\
\hline & & $\mathbf{3 7}^{\mathbf{0}}$ Residencial Maria Isabel \\
\hline & & $\mathbf{3 8}^{\mathbf{0}}$ Vila Brasil \\
\hline & & $3^{\circ}$ Vila Santo Ivo \\
\hline
\end{tabular}

O município se encontra em um processo emergencial, onde as ações se desencadeiam somente em momentos de crise e desastres, lidando de maneira paliativa, com eficácia apenas 
momentânea e incompleta, eliminando as consequências a curto prazo, porém não suas causas.

Através da figura (Figura 4), observa-se os bairros de risco de inundações no município. Segundo relatório da International Strategy for Disaster Reduction (ISDR, 2007), o risco pode ser definido como a probabilidade de consequências prejudiciais, ou perdas previstas (mortes, ferimentos, propriedade, meios de subsistência, interrupção de atividade econômica ou destruição ambiental) resultando das interações entre perigos naturais ou sociais e circunstâncias vulneráveis.

Foram mapeados 39 bairros, desses, observou-se que 28 se encontram como inundações bruscas, 8 em inundações graduais e 3 em graduais e bruscas ao mesmo tempo.

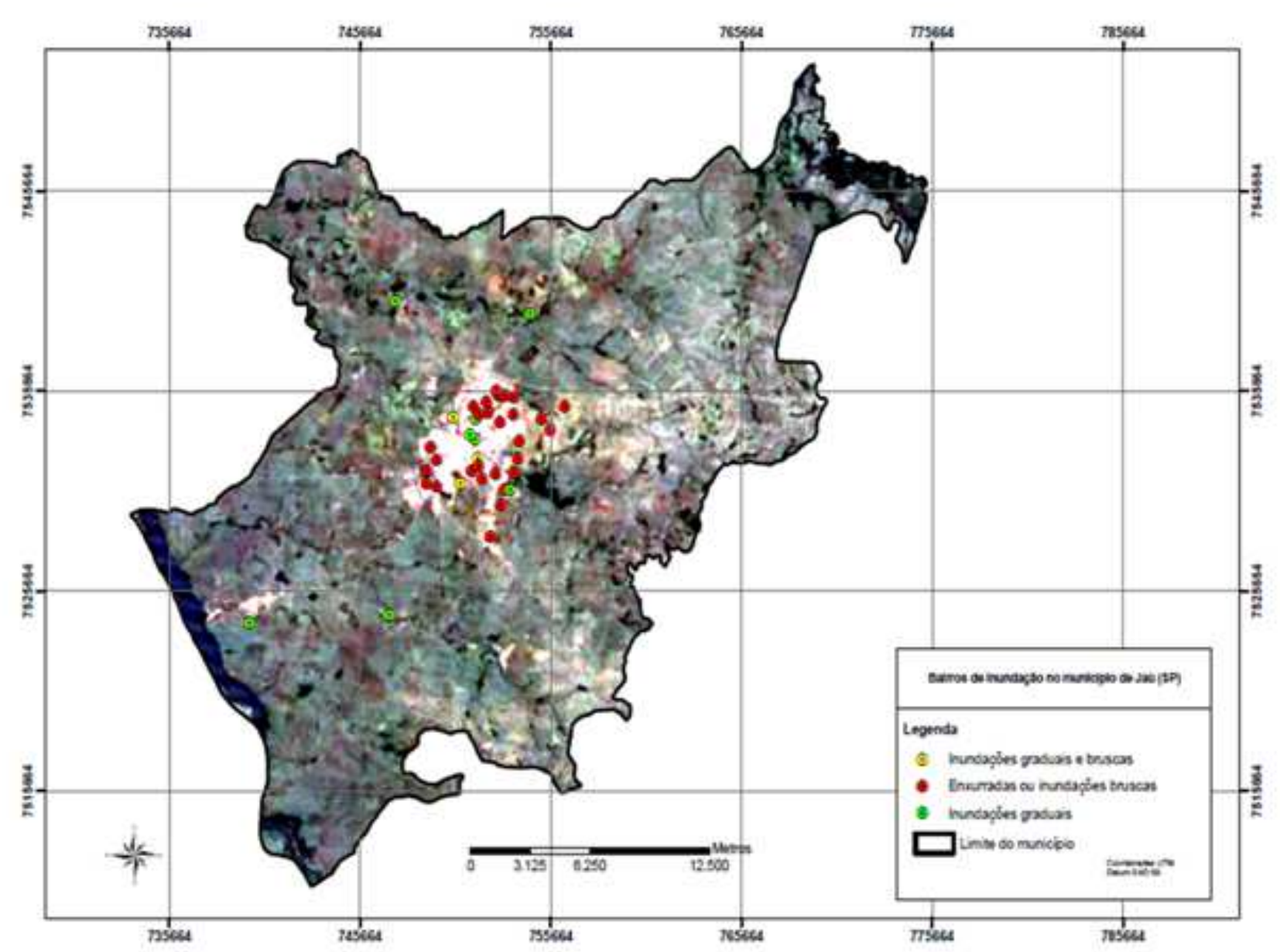

Figura 4. Mapa dos pontos de inundações no município de Jaú

Para uma melhor análise dos bairros de inundação, seccionou-se a malha urbana em três partes, a figura 5 representa a área norte do município, ou seja, os bairros de enxurradas e inundações mais isolados. 




Figura 5. Área norte do município

A figura 6, representa a área sul, também com bairros mais isolados onde ocorrem enxurradas e inundações.

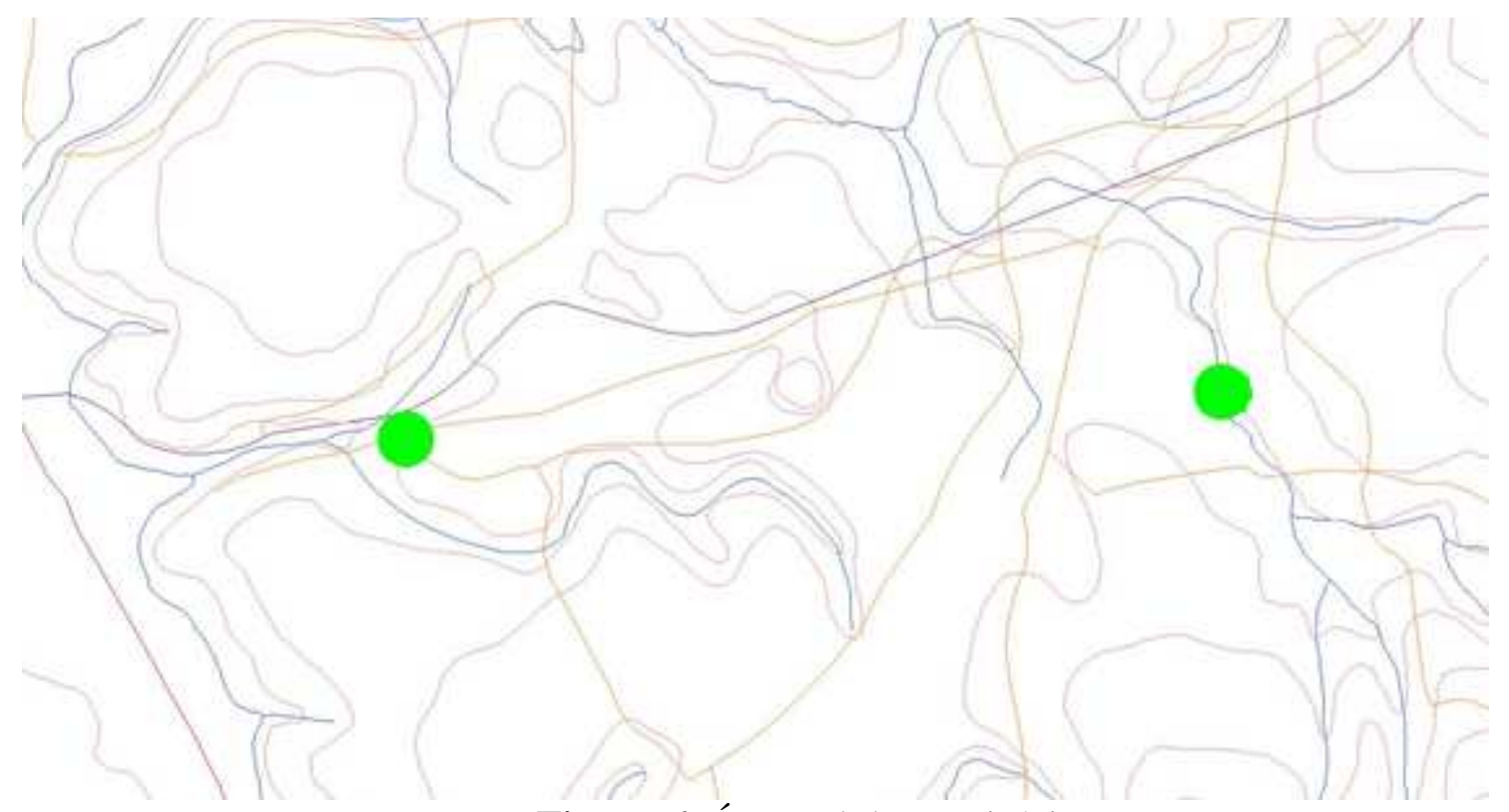

Figura 6. Área sul do município

A figura 7 representa a área central do município onde ocorrem o desastre, sendo marcada pela maior impermeabilização e ocupação humana e consequentemente com o maior número de bairros sujeitos ao problema. 


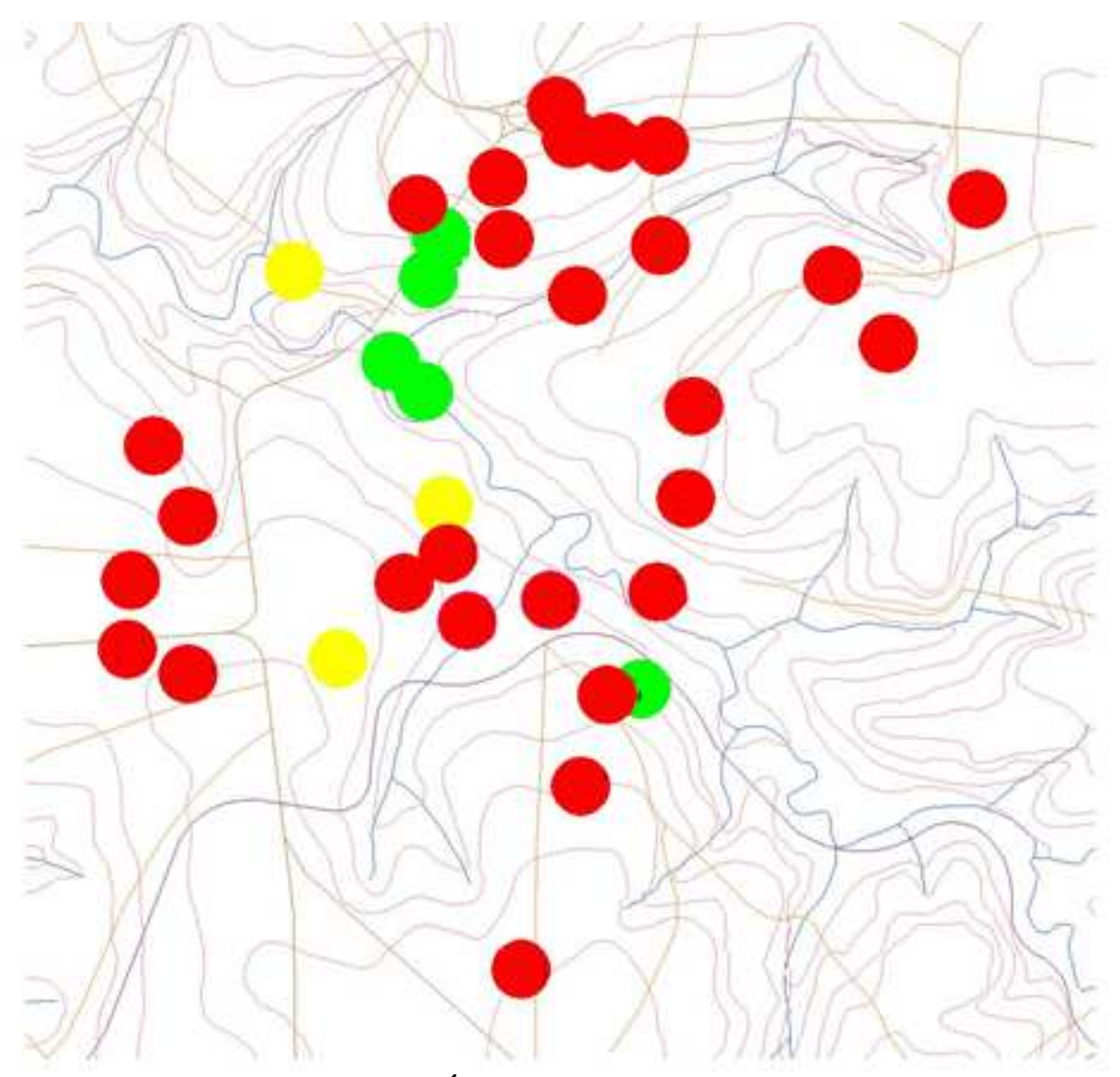

Figura 7. Área central do município

A urbanização acelerada associada à falta de planejamento tem sido a principal responsável pela degradação ambiental de muitos municípios brasileiros. Através dos resultados obtidos para a análise das áreas de risco, foi possível observar que a maior parte dos problemas relacionados a inundações no município de Jaú ocorrem devido a problemas na drenagem. O conjunto de interferência do homem sobre o meio físico tem provocado prejuízos dos quais se destaca com ênfase a diminuição da qualidade de vida da população.

\section{CONCLUSÃO}

Nesse sentido, identificou-se 39 bairros de enxurradas/inundaçõesdos quais, 28 se encontram como inundações bruscas, 8 em inundações graduais e 3 em graduais e bruscas ao mesmo tempo. A análise demonstrou ser o Rio Jaú, principal rio responsável pelas inundações urbanas. Os maiores números de pontos de inundações foram encontrados na região central do município, devido principalmente à maior urbanização.

A análise de risco demonstrou que o município se encontra precário quanto à drenagem urbana, e também a necessidade de sensibilização da população para com as questões ambientais, sem contar a falta de áreas verdes e fiscalização urbana.

\section{REFERÊNCIAS}

BERZ, Gerhard. Flood Disasters: Lessons from the Past - Worries for the Future. Symposiu m on River Flood Defence. v2. Kassel: HerkulesVerlag, 2000.

INTERNATIONAL STRATEGY FOR DISASTER REDUCTION - ISDR - UN. Secretariat. United Nations documents related to disaster reduction 2000- 2007: Advance copy. Geneva, UN. International Strategy for Disaster Reduction (ISDR). Secretariat, 2007.

MORETTI, R. S Terrenos de fundo de vale: Conflitos de propostas, Téchne, São Paulo, 2000. 
POLETO, C. ALTERAÇÕES MORFOLÓGICAS EM UM CANAL FLUVIAL URBANO NO CONTEXTO ANTRÓPICO, SOCIAL E AMBIENTAL: UM ESTUDO DE CASO. Acta $\begin{array}{llllll}\text { Scientiarum. } & \text { Technology (Online), } & \text { v. } & 33, & \text { p. } & 357-364,\end{array}$ (http://periodicos.uem.br/ojs/index.php/ActaSciTechnol/article/view/8288/8288). 2011.

POLETO, C. ; MERTEN, G. H. 2007. URBAN WATERSHED STUDIES IN SOUTHERN BRAZIL. Journal of Urban and Environmental Engineering, v. 1, p. 70-78. (http://periodicos.ufpb.br/ojs2/index.php/juee), 2007.

PORTO, R. Et Al Drenagem Urbana. In: TUCCI, C (Org). Hidrologia: ciência e aplicação. Porto Alegre Ed da UFRGS; São Paulo: EDUSP; ABRH, 1993.

SCHERER, R. B; SANTOS, R.C. Inundações em centros urbanos: impactos ambientais gerados pelo crescimento populacional. RBGA (Pombal - PB - Brasil) v.6, n.1, p. 42 - 45 janeiro/dezembro de 2012.

TUCCI, C. E. M. Gestão das inundações urbanas. Global Water Partnership. Edição em arquivo digital. Brasília, 2005.

TUCCI, C.E.M. Inundações Urbanas. Ed.ABRH. Porto Alegre: 2007. 